\title{
Arquitectura militar. Un patrimonio entre el olvido y la invención
}

\author{
Alfredo J. Morales \\ Departamento de Historia del Arte \\ Universidad de Sevilla
}

\section{Resumen}

La arquitectura militar es uno de los vestigios más representativos de las civilizaciones que poblaron la península. Su continua adaptación a las evoluciones del arte de la guerra fue una constante en su uso hasta que, en el siglo XIX, el sistema de guerra ofensiva y los avances en la industria armamentística, ponen en evidencia la inutilidad de estas edificaciones históricas. Comienza entonces un largo proceso de abandono y de ruina que tendrá como consecuencia la desaparición de buena parte de las mismas. Casi al mismo tiempo, se produce el fenómeno contrario, ya que desde diferentes sectores de la sociedad se inicia un lento proceso de revalorización que conllevará su conservación y protección.

\section{Palabras clave}

Arquitectura militar / Fortificaciones / Murallas / Castillos / Arte de la guerra / Artillería / Legislación del Patrimonio Histórico / Paradores nacionales.

\footnotetext{
"En el mes de mayo de dicho año (1904), este magnífico conjunto de arcos, columnas y marcos de puertas y ventanas esculpidos en mármol fue sacado del castillo por un decorador francés, llamado J. Goldberg, que habitaba en la calle de La Boéite de París, y transportado por vía marítima hasta Marsella y después a París. Juntamente con los elementos que pertenecían al patio, fueron otras tallas del renacimiento, también procedentes del castillo de Vélez, entre ellas el artesonado de uno de los salones y dos puertas" I. Se culminaba con ello la venta de un ámbito clave para la historia de la arquitectura del renacimiento en España, el patio del castillo de Vélez Blanco. A la vez, el patrimonio histórico español sufría uno de los episodios de expolio más deplorables y conocidos. Pero, desgraciadamente, no fue el único, pues muchos otros ejemplos de arquitectura militar desaparecieron o quedaron reducidos a ruinas. Sin embargo, a pesar de tanta destrucción y abandono, aún cuenta el patrimonio cultural hispano con un conjunto numerosísimo y tremendamen-
}

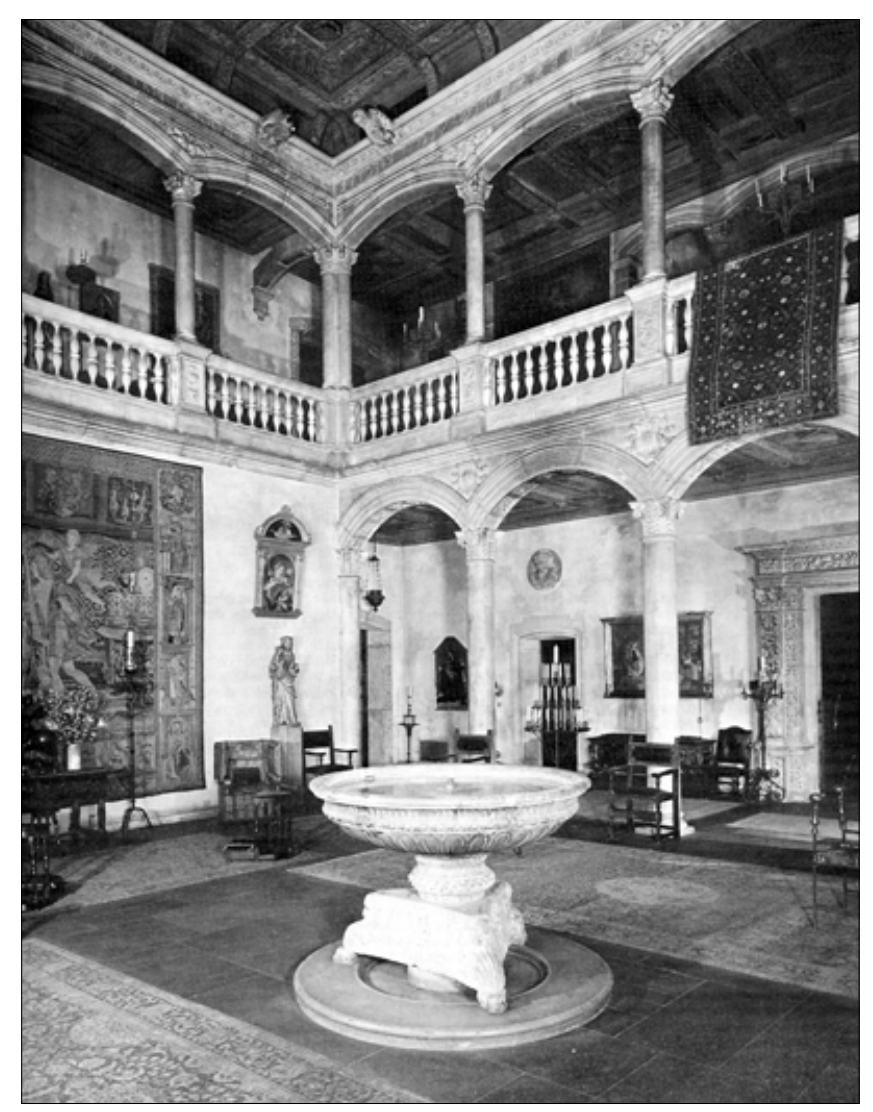

te atractivo de castillos, fortalezas y fortificaciones. Ellos son testimonios privilegiados, aunque en buena medida olvidados, de nuestro pasado.

Ha sido precisamente nuestra peculiar y conflictiva historia la que explica la abundancia de estas construcciones, que aún continúan siendo hitos referenciales de nuestros paisajes urbanos y rurales. No obstante, lo fueron mucho más en el pasado, cuando los castillos y fortificaciones constituían la imagen definitoria de nuestro país, hasta el punto de dar nombre a uno de los principales reinos peninsulares. De ese protagonismo fueron conscientes los viajeros que recorrieron España en los siglos pasados, dejando testimonio de ello en las descripciones y textos de sus itinerarios y en las ilustraciones de sus manuscritos y libros. También advirtieron ese protagonismo los pioneros de la fotografía, al realizar vistas sorprendentes que recogían por igual los quebrados perfiles de los castillos medievales, empinados sobre peñas y roquedales imposibles, como las geométricas y macizas defensas abaluartadas, que surgían de las aguas del mar.

Nuestra arquitectura militar es milenaria. Las diversas civilizaciones que poblaron la península han deja-
I. Patio del Castillo de Vélez Blanco, reconstruido en la Casa Blumenthal de Nueva York. 
do testimonio de sus técnicas y sistemas de defensa. Cada periodo de nuestra historia esta representado en multitud de construcciones defensivas, en las que resultan visibles las huellas y los reflejos de los diferentes técnicas y principios estéticos, de los estilos artísticos imperantes en cada momento. No obstante, siempre han primado las razones funcionales y la adecuación a los medios y procedimientos de la guerra. De hecho, la transformación de los recintos, la complejidad de las estructuras y la multiplicación de elementos y recursos para la defensa han venido motivados por la evolución de las técnicas y tácticas militares y por los avances en el armamento.

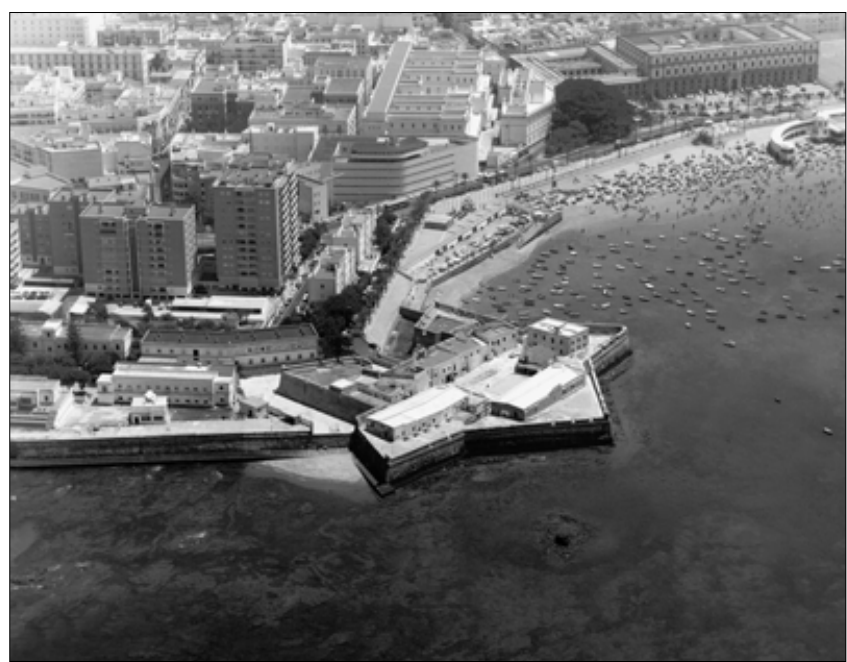

2. Cádiz. Baluarte de San Pedro.

Muchas defensas antiguas siguieron teniendo vigencia en tiempos medievales, por lo que se constituyeron en el núcleo de las nuevas fortificaciones ${ }^{2}$. De hecho, tanto los musulmanes al ocupar la península, como los cristianos cuando iniciaron su ofensiva desde las tierras del norte, se sirvieron de los recintos murados de época romana para sus nuevas necesidades defensivas. Cuando en el siglo XI, tras la caida del Califato de Córdoba, los reinos cristianos procedieron a crear nuevas poblaciones al sur de la línea del Duero, las dotaron de espléndidas murallas. También las dinastías almorávide y almohade reforzaron la seguridad de las tierras de al-Andalus mediante la construcción de nuevos recintos murados y la revitalización de los preexistentes. Será en el siglo XIII cuando se inicie una nueva etapa en el amurallamiento de las ciudades, en buena parte determinado por las necesidades de defensa durante los enfretamientos entre la monarquía y la nobleza castellana. No obstante, las novedades respecto a los anteriores sistemas defensivos fueron escasos, ya que los procedimientos y técnicas militares no sufrieron cambios de importancia.

Fue en el siglo $\mathrm{XV}$, con las nuevas guerras entre las naciones y la aparición en la artillería de los proyectiles metálicos, cuando los castillos y las viejas murallas perdieron su eficacia. Para resistir el fuego de las baterías móviles los ingenieros militares construyeron fortificaciones abaluartadas, con muros más bajos, pero inclinados y de mayor espesor. Estos nue- vos sistemas de defensa garantizaban el control desde el interior de todas las partes exteriores de la fortaleza. Con el perfeccionamiento de estas plazas fuertes fue posible resistir los asaltos de los ejércitos invasores, haciendo que los asedios y sitios se prolongaran en el tiempo. A la par que se perfeccionaron los sistemas defensivos se generalizó una literatura específica sobre la teoría y la práctica del arte militar. De hecho, a lo largo de todo el siglo XVI los textos dedicados a la ingeniería militar conocieron una extraordinaria floración. Entre los escritos españoles sobre la matería hay que destacar el publicado en Madrid, en 1598, por Cristóbal de Rojas, titulado Teoría y práctica de la fortificación ${ }^{3}$. Junto a su labor teórica hay que señalar su importante papel como arquitecto en Sevilla y Sanlúcar de Barrameda, y su decisiva intervención en las fortificaciones de Ceuta, Gibraltar y, especialmente, de Cádiz, tras el asalto de la flota anglo-holandesa en 1596. Tales actuaciones, de las que aún son testimonio algunos de los ejemplos más representativos del rico patrimonio monumental de carácter militar que conserva Andalucía, formaban parte de un programa global de defensa de la monarquía hispana propiciado por Felipe II 4 .

Durante el siglo XVII las principales innovaciones en la arquitectura militar tuvieron origen francés y se debieron a Vauban. No sería hasta comienzos del siguiente siglo, con motivo de la Guerra de Sucesión, cuando aquellas novedades se introdujeran en la arquitectura militar española, posibilitándose su generalización mediante la fundación del cuerpo de ingenieros militares, que estuvo dirigido por Jorge Próspero de Verboon, flamenco al servicio de la corona española. Fueron aquellos los encargados de proporcionar el aparato defensivo a España y a su imperio ultramarino, que alcanzó su culminación durante el reinado de Carlos III5. No obstante, y a pesar del gran esfuerzo desarrollado en la construcción de fortalezas, la invasión de la península ibérica por las tropas de Napoleón demostró el grado de inferioridad existente con respecto a Francia, tanto en defensas, como en infraestructuras viarias y cartografía 6 .

Por otra parte, se estaba imponiendo en aquellos momentos un nuevo sistema de guerra ofensiva, puesto en práctica por el ejército prusiano, que hacía ineficaces las fortalezas abaluartadas. Su inutilidad resultó ya absoluta cuando gracias a la revolución industrial y a las mejoras en la artillería, con los cañones rayados y los obuses cilíndro-ojivales, se logró un mayor alcance, potencia destructiva y precisión de tiro. Los sistemas de fortificación que desde el renacimiento habían servido para proteger las ciudades y las fronteras de las naciones perdieron definitivamente su sentido.

A partir de ese momento se inició un proceso generalizado de abandono de las fortificaciones. Si en Francia habían sido las masas revolucionarias las culpables de la destrucción de numerosas fortificaciones y castillos, en su afán por eliminar los vestigios del oscurantismo y la opresión del régimen monár- 
quico, en España fue la ignorancia y la incuria, la causante de su ruina. De hecho, sin contar con los estragos producidos por las guerras de la Independencia y carlistas y por la revolución de septiembre de 1868, fue el desinterés, la ineficacia y la falta de uso de las pertenecientes a la administración, así como la imposibilibad de mantenimiento, por carencia de recursos, en las que eran de propiedad privada, las que provocaron la ruina y desaparición de buena parte de ellas, o su conversión en barata cantera de la que extraer materiales para nuevas edificaciones. Todo ello se producía en contradicción con el espíritu romántico, que alentó buena parte del siglo XIX y que significó la recuperación de la Edad Media y de sus estilos artísticos, en especial el gótico, y que en arquitectura se expresó mediante el eclecticismo ${ }^{7}$. De la alta consideración que por entonces se tenía de los edificios medievales son testimonio las numerosas ilustraciones que a ellos se dedican en los repertorios de la historia monumental de España, resultado del auge de la historiografía arquitectónica, cuyo ejemplo más representativo es la serie Monumentos arquitectónicos de España, iniciada en 1859.

Sin embargo, la atención y estima por parte de los intelectuales hacia estos testimonios del pasado no condujeron a su conservación. Repasando el conjunto de valiosísimas ilustraciones que enriquecen algunas de las revistas de la época, caso del Semanario Pintoresco Español, El Artista, El Museo Universal y La España Artística y Monumental, sorprende el número de edificios desaparecidos y de insensatos derribos que se sucedieron, sin que se atendieran los preceptos legales y las órdenes promulgamadas, prohibiendo tales manifestaciones de barbarie. Desde las primeras normativas de comienzos del siglo XIX, cuando el concepto de patrimonio era aún impreciso, se establece que los edificios antiguos, entre los que cabe incluir los testimonios del arte militar, debían ser conservados, prohibiéndose, además, la reutilización de sus materiales. No obstante, en aquellos momentos el interés estaba centrado en los restos arqueológicos, como demuestran las disposiciones de 2 de octubre de 1818 y de 19 de septiembre de 1927. Será a partir de la Desamortización de 1835 y de la posterior puesta en venta de los bienes eclesiásticos cuando se abra una nueva y lamentable etapa para todo el patrimonio cultural español, incluso para el de carácter civil, caso de los castillos y fortificaciones. Las generalizadas destrucciones que se sucedieron hacieron temer la rápida desaparición de "los más bellos recuerdos de las artes españolas".

Aún no había transcurrido una década desde la promulgación del decreto de venta de los bienes pertenecientes a las instituciones religiosas suprimidas, cuando mediante una Real Orden de 13 de junio de I 844 se crearon las Comisiones de Monumentos, como entidades responsables del patrimonio español. La organización de las mismas se parecía considerablemente al modelo francés, algo lógico ya que su promotor fue Antonio Gil de Zárate, Director de
Instrucción Pública, quien se había educado en Francia y admiraba las propuestas de la monarquía de Luis Felipe. Gracias a la labor de dichas Comisiones se esbozó un primer inventario de los monumentos y de su estado de conservación, lográndose que se interrumpiera la venta de edificios religiosos, pero sin que se prestara mayor atención a la arquitectura militar. No obstante, el resultado fue bastante dispar, en razón de las personas que integraban las Comisiones Provinciales y sus criterios valorativos, dándose la circunstancia de que algunas, caso de las de Almería, Canarias, Málaga, Pontevedra y Vizcaya, llegaron a informar a la Comisión Central que en sus respectivas provincias no existían monumentos dignos de ser conservados.

Hubiera sido suficiente con haber cumplido las leyes para que se detuviera la fiebre derribista. Sin embargo, el general desinterés y la necesidad de dar salida al cúmulo de edificios antiguos que la Desamortización había puesto en el mercado, no hizo sino incrementar las destrucciones. Y éstas aún se acrecentaron y aceleraron como consecuencia de la Revolución de septiembre de 1868, ante la impotencia e incapacidad de las autoridades. Una vez establecida la República, desde la Academia de San Fernando se pidió al gobierno medidas tajantes para evitar los derribos, argumentando que la riqueza patrimonial de España podía convertirse en "un manantial indirecto de riqueza para los pueblos, puesto que atraen y motivan las visitas de los extranjeros y de los curiosos". El 16 de diciembre de 1873, Emilio Castelar, como presidente del gobierno, firma un decreto en el que se reconocen las tropelías cometidas: "El Gobierno de la República ha visto con escándalo en estos últimos tiempos los numerosos derribos de monumentos artísticos notabilísimos, dignos de respeto, no sólo por su belleza intrínseca, sino también por los gloriosos recuerdos históricos que encierran". Seguidamente se ordena la supresión de los derribos de los edificios públicos "que por su mérito artístico o por su valor histórico deba considerarse como monumento digno de ser conservado" 8 . A pesar de la buena voluntad manifestada en el texto, el decreto resultó ineficaz, debido, entre otras razones, a la caída de la República.

Con anterioridad a ello habían sido muchos los monumentos que habían desaparecido, contándose entre las principales víctimas de los derribos a las murallas que cercaban la mayor parte de las ciudades españolas. Bajo la apariencia de la utilidad pública y el beneficio higiénico, ocultando intereses particulares y especulativos, demostrando la ignorancia y connivencia de las autoridades y el sistemático incumplimiento de la legislación por parte de quienes eran sus principales garantes, se demolieron torres, lienzos de muros, barbacanas y puertas, transformándose radicalmente la imagen externa de las poblaciones. Un mal entendido sentido de la modernidad y el afán por seguir modelos foráneos, dio al traste con un patrimonio singular y único. Las referencias fueron las intervenciones de Haussman en París, entre 1830 y 1844 , con la creación de los 


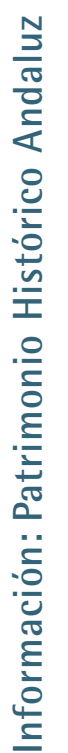

3. Granada. Puerta de Bibarrambla o arco de las Orejas, reconstruido en el bosque de la Alhambra.

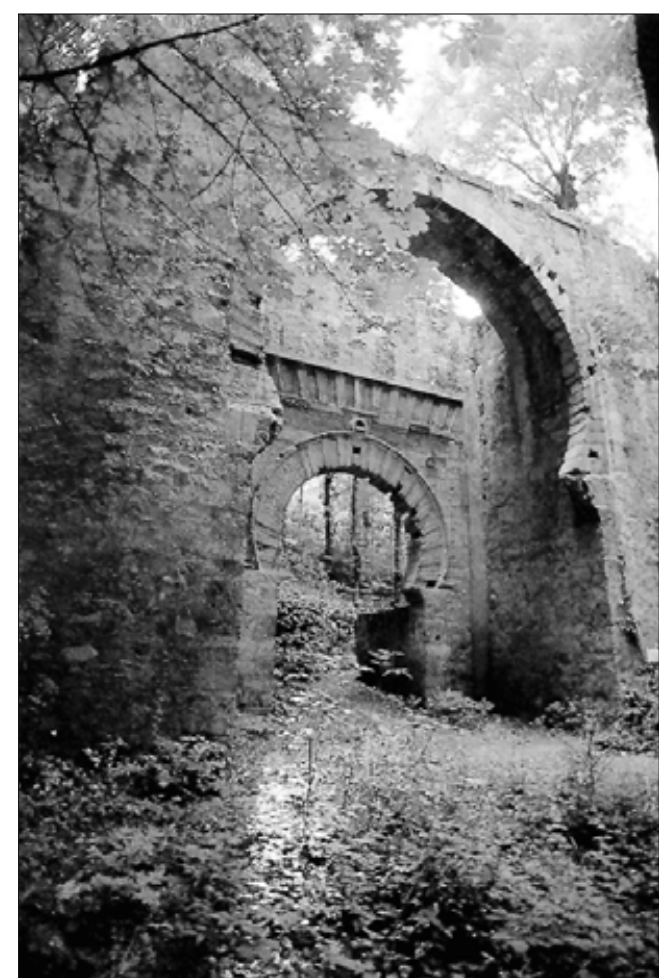

grandes bulevares, las operaciones de Giuseppe Poggi en Florencia, derribando las murallas y construyendo, de 181 I a 1848, nuevos barrios a lo largo de todo el perímetro urbano, o la creación del Ring de Viena, entre 1859 y | 872, con la eliminación de las murallas para unir la ciudad vieja y la moderna mediante un nuevo trazado viario. Tras aprobarse a fines del siglo XIX la Ley de Ensanche de Grandes Poblaciones, se inició un periodo de casi cincuenta años en el que se demolieron las murallas y rellenaron los correspondientes fosos de numerosas ciudades de España, operaciones que los Ayuntamientos liberales justificaron por entender tales estructuras como un símbolo de la opresión.

De la incontrolada política de derribos de murallas se hacía eco Torres Balbás: "Estas murallas de nuestras villas no caen de vejez ni las arruinan los temporales: derribanlas los Municipios como cosas viejas, inservibles y molestas", añadiendo "no faltan pretextos para la destrucción: necesidades de higiene, de urbanización, o el supuesto estado de ruina en que se encuentran, aunque luego tengan que volarlas con dinamita para hacerlas desaparecer. En el fondo, ello es nada más que cuestión de incultura y mal gusto, ignorancia del pasado" 9. Pocos ejemplos son más representativos de lo acaecido en múltiples lugares de España, que el referido a la Puerta de Bibarrambla de Granada, también Ilamado Arco de las Orejas. En junio de 1873 ordenó el ayuntamiento de la ciudad el derribo de dicha puerta, frente al criterio del gobierno, de las academias, de artistas y escritores. Las operaciones se iniciaron de noche y a la luz de las antorchas, sin que la destrucción llegara a completarse. Para preservar sus restos y, en reconocimiento a su valor patrimonial, se procedió en 188 I a declararla monumento nacional. Cuando todo parecía garan- tizar la supervivencia de los restos que permanecían en pie, en 1884, durante el gobierno de Cánovas del Castillo, quien era director de la Real Academia de la Historia, se ordenó el derribo, aduciendo razones de higiene. La noticia fue acogida en Granada con gran regocijo y disparo de cohetes ${ }^{10}$. La demolición no puso fin a la historia de esta puerta, pues entre 1933 y 1935 sus despojos fueron levantados por Torres Balbás en el bosque de la Alhambra, poco más arriba del Arco de las Granadas. Fue posible rehacer su fachada externa, pero no las bóvedas desaparecidas. Aislada y semioculta por la vegetación, en la actualidad es como un arco de triunfo, un testimonio permanente de quienes desde la incultura o la desidia provocaron su derribo.

Al igual que la Puerta de Bibarrambla, otros elementos y testimonios de la arquitectura militar que habían sido declarados Monumento Nacional fueron derribados, poniendo de manifiesto que ni siquiera la resolución administrativa que reconocía su valor singular y, por tanto, obligaba a su conservación, fue capaz de salvarlos de la piqueta. De los muchos casos que podrían recordarse, uno de los más conocidos es el de la Puerta de Santa Margarita en la muralla de Palma de Mallorca, declarada Monumento Nacional en 1908 y destruida cuatro años más tarde, con nocturnidad y mediante el uso de dinamita, por orden del ayuntamiento. En manifiesto contraste con el afán derribista y el incumplimiento de los preceptos legales de los ejemplos anteriores se encuentra el caso de Avila. También fue en 1884 cuando sus murallas fueron declaradas Monumento $\mathrm{Na}$ cional, reconociéndose con ello su valor cultural como singular fortificación medieval y la necesidad de su tutela material por parte del Estado, lo que implicaba la liberación de cargas para el municipio. Si bien se consiguió de este modo salvar la muralla, el entendimiento de la misma como un anillo ideal alrededor de la ciudad provocó la desaparición de los edificios adosados en su perímetro exterior, caso del Alcázar, el Palacio Viejo y la Alhóndiga, así como de otros que enlazaban o se apoyaban en su fachada interna, operaciones que aún se desarrollaban en las últimas décadas del siglo XX 1 . A pesar de los trabajos de "limpieza" desarrollados conforme a un claro proceso de sublimación del monumento y de ciertos excesos en la restauración de este espléndido recinto de murallas, su preservación resultó definitiva para que mundialmente se reconociese su singularidad, por lo que fueron declaradas Patrimonio de la Humanidad en el año 1985.

El caso verdaderamente excepcional de Avila, no puede llevar al olvido a los centenares de castillos, murallas y fortificaciones desaparecidas. Su elevado número hizo incluso imposible incorporar más que unos cuantos ejemplos al revelador estudio de Gaya Nuño titulado La arquitectura española en sus monumentos desaparecidos. El objetivo del mismo era "recoger en un libro aleccionador y sonrojante una porción -la más hiriente y vergonzosa- de los edificios españoles destruidos por la ignorancia o el indiferentismo", dando como resultado final una suerte 
de "catálogo monumental de lo volatilizado, perdido o exiliado". Sin embargo, en su trabajo se procuró "eliminar un tipo de monumento cuya ruina es difícil de evitar: el castillo", debido a su elevado número y al mal estado de conservación de la inmensa mayoría de los existentes. "Los centenares y centenares de castillos españoles, construcciones de los siglos XIII a XV, de carácter marcadamente militar, llevan siglos y más siglos en absoluta perdición, que nadie trató de detener". Por ello del conjunto "de edificios enfermos y sin cura posible, han sido entresacados los que poseían un interés palacial y unas circunstancias decorativas o constructivas propias de residencia urbana" 12. Esto explica que en el libro sólo se hayan recogido algo más de medio centenar de castillos o elementos de arquitectura militar.

La desaparición de buena parte de este patrimonio monumental se produjo con manifiesto incumplimiento de las leyes de protección promulgadas. Durante le primer cuarto del siglo $X X$ fueron dos las disposiciones legales publicadas para regular el patrimonio histórico. La Ley de Excavaciones Arqueológicas de 1911 fue una norma esencialmente reguladora de los bienes arqueológicos, siendo sus referencias a los inmuebles tan genéricas que muy poca repercusión podían tener en la conservación de la arquitectura militar. Y ello a pesar de los numerosos testimonios de ésta que no sólo tenían un valor arqueológico, sino que también resultaban protegidos por el marco cronológico de aplicación establecido por la propia ley. La precaria protección otorgada a los inmuebles hizo necesaria una nueva normativa que fue promulgada en 1915 con el título de Ley de Monumentos Arquitectónicos-Artísticos. En su contenido se aprecian notables avances conceptuales, mientras se debe lamentar la debilidad de los instrumentos de control establecidos, aunque se trata del primer intento por normar la protección y por definir por medio de actos administrativos el objeto de la ley. Uno de sus principales aciertos fue la eliminación de cualquier limitación cronológica o estilística, así como el establecer la catalogación como base para la aplicación de la ley, sumándose de esta manera a las corrientes europeas más vanguardistas en materia de patrimonio. No obstante, la ley preveía la posibilidad de derribar edificios que hubieran sido declarados o que tuvieran expediente de declaración incoados, tras autorización del Ministerio de Instrucción Pública. Por otra parte, se consentía el traslado de inmuebles, fijándose el derecho de tanteo de la administración cuando el derribo no se hubiese efectuado para reconstruir el edificio en otro punto del territorio nacional.

Tales normativas no contribuyeron de manera efectiva a la conservación de la arquitectura militar, siendo posiblemente éste el capítulo de los bienes inmuebles sobre el que se ejerció menor control. Los derribos se sucedieron y también se produjeron algunos traslados, reaprovechamientos de piezas singulares y la salida del territorio nacional de elementos de considerable valor artístico. Así ocurrió con el castillo de Curiel de los Ajos, en la provincia de Valladolid, obra de transición del siglo XIV al XV, que comenzó a ser desguazado en 1919 y del que solo se salvaron las techumbres de madera compradas por el anticuario Lafora y la columnata de su patio, adquirida por el conde de las Almenas y reconstruida en su finca "Canto del Pico", de Torrelodones ${ }^{13}$.

Con objeto de poner fin a esta continuada pérdida patrimonial la Ley del Tesoro Artístico Nacional de 1926 prohibió la exportación de bienes, al establecer que estos quedaban adscritos al suelo de la nación, impidiéndose la salida del país incluso de los que hubieran sido excluidos del catálogo ${ }^{14}$. No obstante y a pesar del voluntarismo de esta nueva norma la situación no cambió sustancialmente. En 1933 promulgaba el gobierno de la Segunda República la Ley de Patrimonio Artístico Nacional, norma de signo progresista y muy innovadora, que recogía conceptos y criterios vanguardistas, muchos de ellos emanados de la "Carta de Atenas", de 1931. Sin embargo, también ofrecía algunas deficiencias y aspectos negativos, siendo el más destacado la introducción del factor cronológico, al señalar que quedaban sometidos a la ley los bienes de antigüedad no inferior a cien años. Aunque después indicaba que igualmente quedaban sujetos a la norma los bienes que sin ser centenarios presentaran un valor histórico o artístico indiscutible, la realidad es que la limitación temporal se tomó como referencia básica. Entre los puntos de interés de esta ley cabe señalar los referidos a los criterios establecidos para la restauración de monumentos, de claro origen conservacionista, los relativos a la prohibición de efectuar obras no aprobadas, los que reglamentaban el uso de los inmuebles y los que prohibían la exportación de edificios de más de un siglo de existencia. El Reglamento de dicha ley apareció en abril de 1936, es decir, tres meses antes de iniciarse la guerra civil. Durante la misma, las pérdidas que sufrió el patrimonio histórico español fueron cuantiosísimas. A los numerosos bienes muebles e inmuebles que desaparecieron hay que agregar los que resultaron gravemente dañados y que, posteriormente, no se llegaron a restaurar. $Y$ todo ello a pesar de las medidas y normas de protección adoptadas durante la contienda tanto por uno, como por otro bando ${ }^{15}$. Por obvias razones, el régimen político triunfante prestó especial atención a los bienes de carácter religioso, cuya recuperación y restauración utilizó como medio de propaganda. En un primer momento no se prestó atención a los castillos y a la arquitectura militar, por lo que se agravó el deficiente estado de conservación que presentaban antes de la guerra, causante también de la ruina de buena parte de ella. Como excepción puede señalarse la restauración del Alcázar de Toledo, si bien los trabajos emprendidos tuvieron un carácter propagandístico, pues su finalidad fue la exaltación de los heroicos hechos bélicos que en él habían tenido lugar.

A pesar de las radicales diferencias ideológicas del nuevo régimen político respecto al republicano, se mantuvo vigente su ley de patrimonio de 1933. Ello fue posible, entre otras cosas, por la falta de celo 


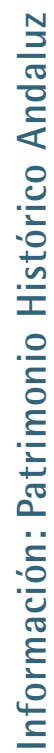

que habitualmente demostró la administración para cumplirla. No obstante, también se comprueba su interés por adecuar dicha ley a las nuevas necesidades de protección del patrimonio mediante las modificaciones y adiciones que a su texto y al posterior reglamento se sucedieron con el paso de los años. Entre las diferentes normas promulgadas, una se destinó específicamente a la protección de los castillos. Al igual que los posteriores decretos sobre la protección de escudos, piedras heráldicas, cruces de término, etc, y el referido a los hórreos y cabazos antiguos, se pretendía una tutela extensiva y genérica de ciertos elementos singulares del patrimonio, que por su carácter simbólico o por dificultades intrínsecas, hacían imposible su declaración individualizada. El decreto sobre protección de los castillos es-

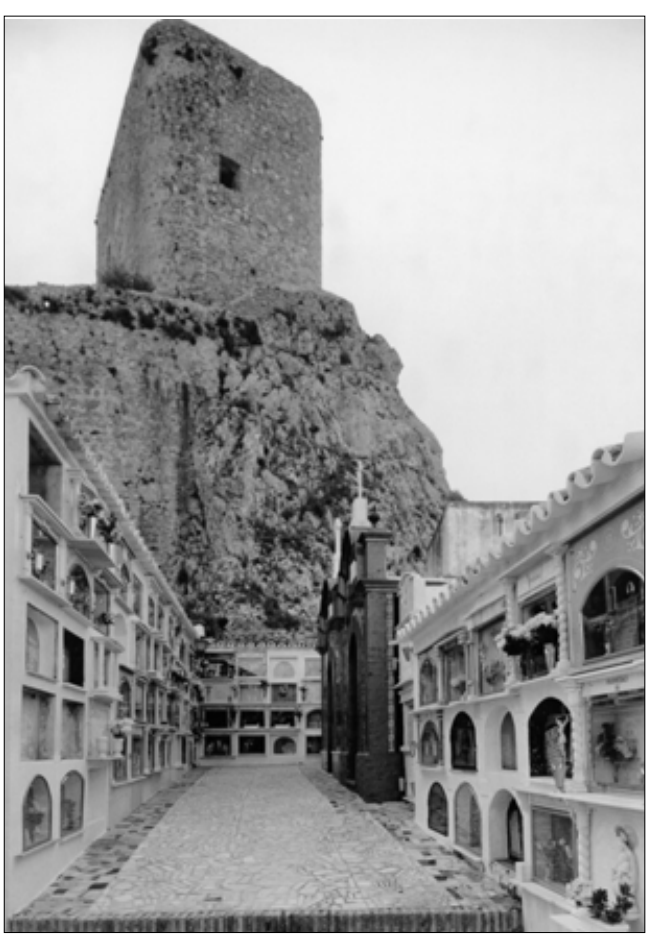

5. Zafra. Parador Nacional. pañoles se promulgó el 22 de abril de 1949, haciéndose coincidir con la celebración de una exposición organizada por Casto Fernández Shaw en el Círculo de Bellas Artes de Madrid. Su preámbulo, suma de visión romántica y de propaganda política, señala que "una de las notas que dan mayor belleza y poesía a los paisajes de España es la existencia de ruinas de castillos en muchos de sus puntos culminantes, todas las cuales, aparte de su extraordinario valor pintoresco, son evocación de la historia de nuestra Patria en sus épocas más gloriosas, y su prestigio se enriquece con las leyendas que en su torno ha tejido la fantasía popular". Seguidamente reconoce que por desgracia "estos venerables vestigios del pasado están sujetos a un proceso de descomposición. Desmantelados y sin uso casi todos ellos, han venido a convertirse en canteras cuya utilización constante apresura los derrumbamientos, habiendo desaparecido totalmente algunos de los más bellos. Imposible es, salvo en casos excepcionales, no solamente su reconstrucción, sino aun las obras de mero sostenimiento; pero es preciso, cuando menos, evitar, los abusos que aceleren su ruina". Por ello y con independencia de su grado de ruina, los castillos se situaban bajo la protección del Estado, que asumía la responsabilidad de evitar las intervenciones que alterasen su carácter o que favorecieran su derrumbamiento.

Si bien el anterior decreto no tuvo consecuencias inmediatas, si propició a medio plazo la aparición de una nueva conciencia sobre la importancia patrimonial de los castillos. A las iniciativas de la propia administración, como el desarrollo de ciertos trabajos de restauración y la celebración anual del día de los castillos, se sumó la constitución en noviembre de 1952 de la Asociación de Amigos de los Castillos. Esta entidad publicaba en mayo-junio del año siguiente el primer número de un modesto boletín, que en 1967 se convierte en revista con el nombre de Castillos de España ${ }^{16}$. A la vez de la publicación se montaron exposiciones en Madrid, Granada, Barcelona, París, Londres y Washington, con objeto de difundir la "riqueza castellológica" de España. Dicha asociación ostentó durante una serie de años la representación en nuestro país de "Europa Nostra", Federación Internacional de las Asociaciones para la Salvaguardia del Patrimonio Natural y Cultural Europeo, realizando una importante labor de difusión, conservación, restauración y valoración de los castillos hispánicos. Dentro de esas tareas cabe destacar su presencia en la Conferencia que como contribución previa al Año Europeo del Patrimonio Arquitectónico 1975, se celebró en Copenhague en noviembre de 1973, con el título "Working Together: Tourism and Conservation". Además, en julio del mismo año y en la reunión preparatoria del Año Europeo del Patrimonio Arquitectónico, celebrada en Zurich, se presentó por el Instituto Internacional de Castillos (I.B.I), al que estaba incorporada la Asociación Española de Amigos de los Castillos, un proyecto de "Estatutos de Castillos y Mansiones Históricas de propiedad privada", que fue comentado y ampliamente difundido por dicha Asociación 17. 


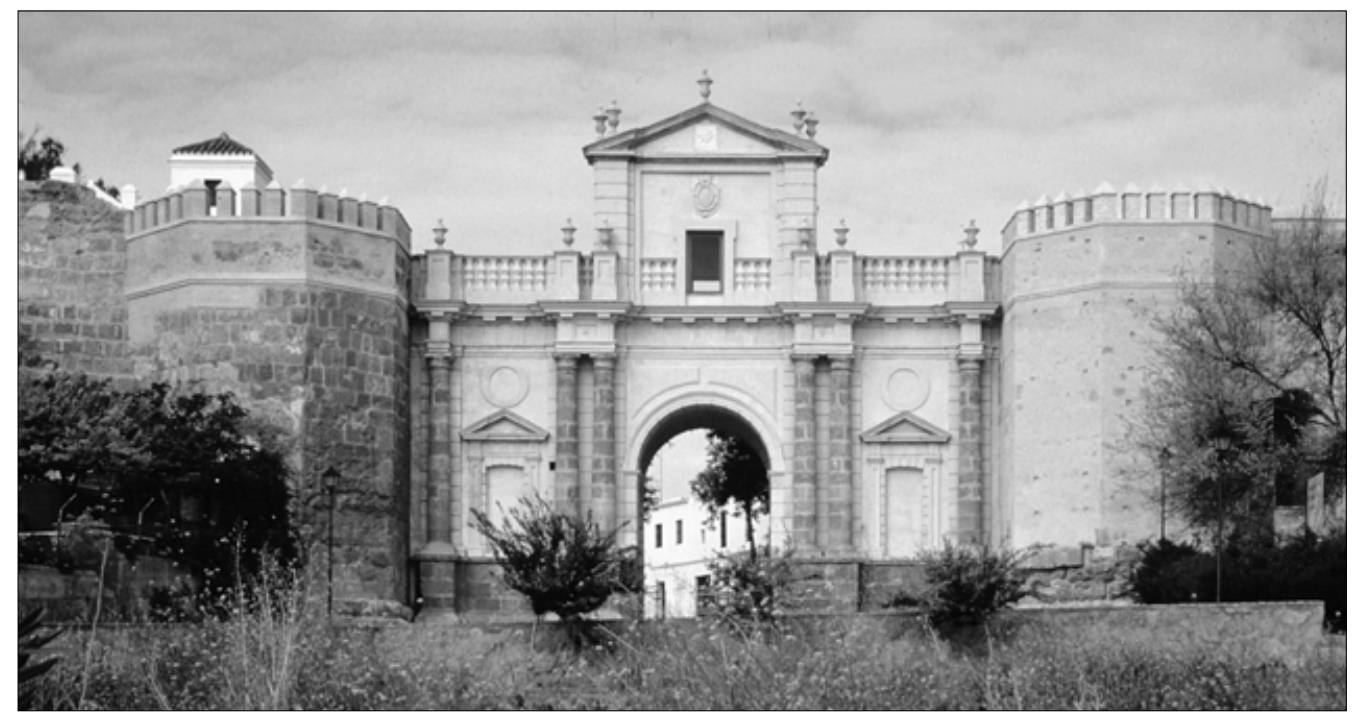

Prueba del compromiso de protección de los castillos adquirido con la promulgación del decreto de 1949, fue la elaboración del inventario de los mismos, conforme estaba previsto en el articulado del propio decreto. Para ello se siguieron las propuestas del Consejo de Europa, en su programa de "Inventario de Protección del Patrimonio Cultural Europeo". De este modo se realizó el "Inventario de Protección de los Monumentos Militares", en el que se llegaron a registrar casi 5.200 "objetos", que incluía no solo los castillos propiamente dichos y los recintos amurallados urbanos medievales, sino también las torres de defensa aisladas, las atalayas de costa, los fuertes y recintos abaluartados, las casas de vivienda o labor, iglesias y puentes fortificados e incluso fortines fusileros, siendo los límites cronológicos de dichos monumentos los años $71 \mid$ y |9|4. De todos los testimonios de la arquitectura militar inventariados, aquellos que podrían considerarse como castillos arquetípicos alcanzaban la cifra de trescientos. Casi doscientos de ellos se hallaban en estado de ruina definitiva, por lo que se proponía la consolidación de los restos. Existía, por otra parte, un numeroso conjunto de castillos que además de restaurarse se consideraban factibles de revitalización. Esta fue la labor emprendida por muchos propietarios particulares. Siguiendo postulados dispares, aunque con predominio de los criterios estilísticos, se salvaron de la ruina importantes edificios. Es el caso de los castillos de Mequinenza (Zaragoza) Peratallada y Vulpellac (Gerona) y La Roca (Barcelona).

Un tercer grupo de castillos lo integraban aquellos a los que las restauración podía hacer rentables. Fueron estos los seleccionados, primero por la Dirección General de Turismo y posteriormente por el Ministerio de Información y Turismo, para establecer en ellos los paradores, establecimientos hoteleros destinados a crear la infraestructura demandada por el creciente turismo. Las tareas de adecuación de las viejas estructuras medievales se emprendieron al margen de la labor desarrollada por los organismos de la administración responsables de la conservación del patrimonio, por lo que los resultados obtenidos no siempre son ejemplo de respeto hacia los monumentos. En algunos casos la adecuación de los viejos castillos medievales para su nueva función resultaba prácticamente imposible, por lo que se optó por adicionarle edificios modernos, que casi llegaban a anular al monumento que se pretendía recuperar. Así ocurrió con el castillo de Santa Catalina de Jaén. Otras veces las limitaciones que imponían los castillos se avenían mal con la rentabilidad del establecimiento hotelero, por lo que las transformaciones resultaron agresivas, como en el $\mathrm{Pa}$ rador Marqués de Villena, situado en el castillo de Alarcón. Una tercera solución fue aprovechar construcciones anejas a los castillos, más fácilmente adaptables, y actuar menos en aquellos. Los resultados fueron en ocasiones aceptables, caso del Parador de Zafra, aunque las profundas transformaciones que se efectuaron en otros casos, como en Sigüenza y Oropesa, llegaron a desvirtuar los propios monumentos. Y a ello también contribuyó el afán por dotar a los ambientes de una escenografía folklorista y pintoresca, que no respetaba la realidad histórica y el valor documental de los edificios. El historicismo se adueñó de los interiores, que fueron decorados con carácter grandilocuente y mediante reproducciones en estilo, de bajísima calidad, dando lugar a conjuntos manifiestamente "kitsch".

Este tipo de operaciones que pretendían la recuperación de castillos y elementos de la arquitectura militar mediante su utilización como establecimientos hoteleros alcanzaron un considerable éxito, llegando a exportarse a otros países, especialmente hispanoamericanos. Con el pretexto de recuperar las antiguas estructuras militares para dar servicio al turismo, se planteaban agresivas operaciones que realmente significaban su desvirtuación y anulación. A veces, las propuestas de nuevas construcciones hoteleras se hacían de espaldas a la propia realidad monumental de los recintos militares en los que se iban a levantar. Así ocurrió con el proyecto de hotel en el interior del Alcázar de Jerez de la Frontera, elaborado en 1958 por Luis Gutiérrez Soto y del que se llegó a levantar su estructura de hormigón armado, permaneciendo en pie hasta 1981, año en que se derribó 18 .
6. Carmona.

Puerta de Córdoba. 
Apenas transcurridos cuatro años de esa última fecha, se promulgaba la última y vigente Ley del Patrimonio Histórico Español. Aún considerando sus avances teóricos y la importancia de los instrumentos que establece para la protección del patrimonio, pocas novedades aporta sobre la arquitectura militar, a no ser su consideración como Bien de Interés Cultural, según se especifica en las disposiciones adicionales de la mencionada ley. Con anterioridad a su promulgación ya habían recibido las Comunidades Autónomas las competencias plenas en materia de patrimonio, encontrándose entre ellas las relativas a la conservación y restauración de monumentos. Con la diversificación de las administraciones intervinientes sobre el patrimonio y la incorporación a tales tareas de nuevos técnicos, se produjo una pluralidad de tendencias, suscitándose la polémica en torno a la relación del diseño nuevo, respecto a la arquitectura antigua. En razón de ello las actuaciones han sido de muy variado signo. Junto a restauraciones que han procurado valorar y potenciar el monumento, mediante el control y la limitación de las incorporaciones, otras han hecho del nuevo diseño el protagonista de las intervenciones, aunque para ello se haya transformado irreversiblemente la arquitectura histórica. Como es lógico, la arquitectura militar no se ha librado de esta contradictoria situación. Así, a la restauración de la Puerta de Córdoba en Carmona (Sevilla), llevada a cabo por Antonio Tejedor, recuperando las cualidades arquitectónicas y los valores del monumento sin renunciar a la obra nueva, se opone el protagonismo del nuevo diseño y la invención frente a la arquitectura histórica, que caracteriza el trabajo de Francisco Jurado, en el castillo de Bétera (Valencia) 19

En el momento presente, la arquitectura militar parece haber superado ya la etapa de desprecio y olvido que vivió durante años, siendo numerosos los estudios y las actuaciones que pretenden tanto su conservación y restauración, como su difusión, tal y como corresponde a una parte sustancial del patrimonio histórico español. No obstante, aún valorando esta nueva situación, resulta evidente que es mucho lo que resta por hacer, siendo de esperar un cambio de actitud, no solo en lo referente a la distribución de los recursos a ella destinado, sino especialmente en el entendimiento y valoración de su importancia, como excepcionales documentos históricos, a pesar del estado ruinoso y fragmentario que mayoritariamente presenta.
I. Cfr. RAGGIO, Olga: "El patio de Vélez Blanco, un monumento señero del Renacimiento", en Anales de la Universidad de Murcia. Filosofía y Letras. Volumen XXVI. Núm. 2-3. Págs. 23I26I. El patio se encuentra actualmente reconstruido en el Metropolitan Museum of Art, de Nueva York.

2. Sobre el proceso de amurallamiento de las ciudades castellanas en tiempos medievales y sobre los valores y funciones de las murallas puede verse VALDEÓN BARUQUE, Julio: "Reflexiones sobre las murallas urbanas de la Castilla medieval", en DE SETA, Cesare y LE GROFF, Jacques (eds.): La ciudad y las murallas. Madrid, 1991. Págs. 67-87.

3. Los textos de Cristóbal de Rojas sobre fortificación han sido publicados con un comentario preliminar por GUTIERREZ, Ramón: Tres tratados sobre fortificación y milicia. Madrid, 1985

4. Al respecto puede verse MORALES, Alfredo !.: "La defensa del imperio filipino",en Catálogo de la Exposición Las sociedades ibéricas y el mar a finales del siglo XVI. Madrid, 1998. Págs. |67-190.

5. Al respecto puede consultarse CAPEL, Horacio; SÁNCHEZ, Joan Eugeni y MONCADA, Omar: De Palas a Minerva. La formación científica y la estructura institucional de los ingenieros militares en el siglo XVIII. Barcelona, 1988.

6. Un interesante estudio sobre el tema es el debido a BONET CORREA, Antonio: Cartografía militar de plazas fuertes y ciudades españolas. Siglos XVII-XIX: planos del Archivo Militar Francés. Madrid, 1991.

7. Sobre este tema puede verse ISAC, Angel: Eclecticismo y pensamiento arquitectónico en España. Discursos, revistas, congresos 1846-1919. Granada, 1987

8. Sobre este decreto y las anteriores normas legales puede consultarse Legislación sobre el Tesoro Artístico de España. Madrid, 1957.

9. Cfr. TORRES BALBÁS, Leopoldo: "Las murallas que caen", en Arquitectura. Año IV. 1922. Págs. 69-75.

10. Idem. Pág.72.
I I. Véase HERNÁNDEZ DÍAZ, Angel: "La conservación de las murallas de Avila", en La ciudad y sus murallas. Conservación y Restauración. Granada, 1996. Págs. 161-179.

12. Cfr. GAYA NUÑO, Juan Antonio: La arquitectura española en sus monumentos desaparecidos. Madrid, 1961. Págs. 35 y 37.

13. Cfr. GAYA NUÑO, Juan Antonio: Op. Cit. Págs. 120-I24

14. Para una aproximación a esta normativa legal puede consultarse MORALES, Alfredo J.: Patrimonio histórico-artistico. Conservación de bienes culturales. Madrid, 1996. Págs. 43-54.

15. Sobre el particular existe un estudio de ALTED VIGIL, Alicia: Política del nuevo estado sobre el patrimonio cultural y la educación durante la guerra civil española. Madrid, 1984.

16. Véase Castillos de España. Número 68, enero-marzo de 1970. Pág. 9.

17. Cfr. Los castillos en su medio ambiente y en relación con el turismo cultural. Número 10 (77). Extraordinario (Marzo 1973), de Castillos de España. Págs. 52-61. Número patrocinado por la Comisaría Nacional de Turismo, del Ministerio de Información y Turismo, como contribución española a la preparación del Año Europeo del Patrimonio Arquitectónico

18. Véase AROCA VICENTI, Fernando: "Nuevas aportaciones a la obra de los arquitectos Luis Gutiérrez Soto y Antonio Sánchez Esteve", en Laboratorio de Arte. N 13, 2000. Págs. 435-436.

19. Sobre la primera véase TEJEDOR CABRERA, Antonio: "La restauración de la Puerta de Córdoba en Carmona: del proyecto a la obra", en PH. Boletín del Instituto Andaluz del Patrimonio Histórico. №33, Diciembre 2000. Págs. I40-I50. Asímismo, TEJEDOR CABRERA, Antonio y LINARES GÓMEZ DEL PULGAR, Mercedes: "La musealización del monumento. Proyecto para un centro de recepción de visitantes", en Idem. Págs. I58-16I. Para el segundo ejemplo consúltese JURADO JIMÉNEZ, Francisco: "Rehabilitación de la casa-castillo de Bétera, Valencia", en Jornadas sobre restauración y conservación de monumentos. Madrid, 24 y 25 de abril de 1989. Madrid, 199I. Págs. 165-176. 